\title{
Conversion in minimally invasive cardiac surgery
}

\author{
Om Prakash Yadava ${ }^{1}$ (D) Filip Casselman ${ }^{2}$
}

Received: 24 October 2018 / Accepted: 29 October 2018 / Published online: 4 December 2018

(C) Indian Association of Cardiovascular-Thoracic Surgeons 2018

\begin{abstract}
In a direct conversation, Dr.Yadava discusses the issue of conversion to sternotomy in Minimally Invasive Cardiac Surgery (MICS) with Dr. Fillip Casselman. The training threshold, reasons for conversion and proper patient selection have been emphasized.
\end{abstract}

Keywords $\mathrm{CABG} \cdot$ Minimally invasive cardiac surgery $\cdot$ Minimally invasive mitral surgery

Dr. Casselman emphasizes (video) that there is a significant learning curve to MICS and the threshold is around 50 cases for a senior surgeon although a number of 75 has been suggested in the literature [1]. The incidence of conversion is around $2-3 \%$. For minimally invasive mitral surgery and for coronary artery bypass surgery (CABG), both of which require thoracic approach; the main reason for early conversion (50\% of cases) is the presence of unexpected lung adhesions [2]. Prof. Casselman feels this should ideally be not called a conversion, but rather a strategy change. In aortic valve replacement, however, which is carried out through a sternotomy, lung adhesions do not have much role and the main reason for conversion is cannulation issues [2]. Dr. Yadava observes that with subclinical inflammation of diseases like rheumatic fever and tuberculosis existing virtually in epidemic proportions in a country like India, the consequent lung adhesions may be a very important limiting factor in choosing minimally invasive approach. Dr. Casselman re-emphasizes that in presence of significant lung adhesions, it is prudent

Electronic supplementary material The online version of this article (https://doi.org/10.1007/s12055-018-0768-2) contains supplementary material, which is available to authorized users.

Om Prakash Yadava

op_yadava@yahoo.com

1 Indian Journal of Thoracic and Cardiovascular Surgery, National Heart Institute, New Delhi, India

2 Department of CTVS, OLV Clinic, Aalst, Belgium to convert rather than persist with MICS. The main reason, however, for late conversion is either bleeding or other medical conditions necessitating conversion. The mortality in these late conversions is three to five times higher, and at times, is related more to the reason for conversion rather than the conversion itself. For example, in atrio-ventricular (AV) rupture, the mortality is obviously likely to be high, as compared to a conversion for bleeding from the pacemaker site.

Patient selection, especially for beginners, is of prime importance in avoiding conversions and due attention should be paid to body habitus, obese patients should be avoided, as also magnetic resonance imaging (MRI) screening for femoro-iliac vessels should be a routine for all patients to avoid any cannulation-related problems [3].

Publisher's Note Springer Nature remains neutral with regard to jurisdictional claims inpublished maps and institutional affiliations.

\section{References}

1. Holzhey DM, Seeburger J, Misfeld M, Borger MA, Mohr FW. Learning minimally invasive mitral valve surgery. A cumulative sum sequential probability analysis of 3895 operations from a single high-volume center. Circulation. 2013;128: 483-91.

2. Van der Merwe J, Van Praet F, Stockman B, Degrieck I, Vermeulen Y, Casselman F. Reasons for conversion and adverse intra-operative events in endoscopic Port-Access atrioventricular valve surgery and minimally invasive aortic valve surgery. Eur J Cardiothorac Surg. 2018;54:288-93.

3. Jeanmart H, Casselman FP, De Grieck Y, et al. Avoiding vascular complications during minimally invasive totally endoscopic intracardiac surgery. J Thorac Cardiovasc Surg. 2007;133:1066-70. 